\title{
Association between Various Brain Pathologies and Gait Disturbance
}

\author{
Alexandra M.V. Wennberg ${ }^{a}$ Rodolfo Savica ${ }^{a, b} \quad$ Michelle M. Mielke ${ }^{a, b}$ \\ Departments of a Health Sciences Research and ${ }^{b}$ Neurology, Mayo Clinic, Rochester, MN, USA
}

\section{Keywords}

Neuropathology · Gait · Aging · Musculoskeletal system · Neural activation

\begin{abstract}
Background: Approximately $30 \%$ of older adults have disrupted gait. It is associated with increased risk of cognitive decline, disability, dementia, and death. Additionally, most older adults present with 1 or more neuropathologies at autopsy. Recently, there has been an effort to investigate the association between subclinical neuropathology and gait. Summary: We reviewed studies that investigated the association between gait and neuropathologies. Although all pathologies reviewed were associated with gait, grey matter atrophy was most consistently linked with poorer gait performance. Studies investigating the association between white matter and gait focused primarily on total white matter. Future research using more parsed regional analysis will provide more insight into this relationship. Evidence from studies investigating neuronal activity and gait suggests that gait disruption is associated with both under- and overactivation. Additional research is needed to delineate these conflicting results. Lastly, early evidence suggests that both amyloid and tau aggregation negatively impact multiple gait parameters, but additional studies are warranted. Overall, there was substantial methodological heterogeneity and a paucity of longitudinal studies. Key Messages: Longitudinal studies mapping changes in different types of neuropathology as they relate to changes in multiple gait parameters are needed to better understand trajectories of pathology and gait.

(C) 2017 S. Karger AG, Basel
\end{abstract}

\section{Introduction}

Gait abnormalities affect approximately $30 \%$ of older adults [1]. Gait decline is associated with an increased risk of functional and cognitive decline, disability, dementia, and death [2, 3]. Gait parameters can be classified into 3 categories: spatial (e.g., stride length), temporal 
(e.g., support time), and spatiotemporal (e.g., cadence). Intraindividual variation in gait parameters (e.g., stance time variability) has also been shown to be a strong predictor of negative clinical outcomes [4,5]. Additionally, tests such as the timed up-and-go (TUG) can be used to evaluate gait and mobility [6].

Gait is a complex task involving the coordination of both the central nervous system (CNS) and musculoskeletal system [7]. It also requires coordination across regions of the brain [7]. Sensorimotor regions are of course required to initiate, sustain, and coordinate mobility. Recent research has shown that regions involved in higher-level cognitive functioning and memory, including the prefrontal cortex, hippocampus, and cerebellar regions, are also required to coordinate mobility. However, the exact extent of the role of brain regions in gait is not yet well defined.

Neurodegenerative disorders (e.g., Parkinson disease [PD], Huntington disease [HD], etc.) often present with gait dysfunction, suggesting a connection between the CNS and gait. A recent review hypothesized that, among older adults, CNS dysfunction is the leading cause of mobility impairment (defined as restriction in moving through one's environment, including gait dysfunction) [8]. Neuropathologies are associated with multiple neurodegenerative diseases in the aging brain. For example, amyloid beta $(A \beta)$ plaques and neurofibrillary tangles are the hallmarks of Alzheimer disease (AD) [9-12]. However, the accumulation of neuropathology is common even among older adults without a clinical diagnosis of a neurodegenerative disease. Indeed, approximately $35 \%$ of cognitively normal (CN) adults between ages 70 and 79 and $57 \%$ of $C N$ adults between ages 80 and 89 have substantial cerebral $A \beta$ deposition [13]. The toxic and atrophic effects of these pathologies may result in impaired ability of the brain to coordinate gait.

Although multiple studies have examined the association between brain pathology and gait dysfunction in neurodegenerative diseases, fewer studies have investigated the associations between subclinical neuropathology and gait [7]. As an initial step, we evaluated the literature examining neuropathology and gait among nondemented, aging individuals, and highlighted areas for future research. Specifically, we investigated white matter (WM) and grey matter (GM) atrophy, neuronal activity as measured by cerebral glucose metabolism, and $\mathrm{A} \beta$ and tau. The majority of studies investigating the association between subclinical neuropathology and gait have focused on cerebrovascular pathology (e.g., WM hyperintensities [WMHs]). The association between greater cerebrovascular pathology and poorer gait performance has been reviewed in depth by others $[14,15]$. Because less is known about the effect of other types of neuropathologies and gait, we focused on summarizing the evidence of noncerebrovascular pathology and gait in the present review. We aimed to determine whether patterns emerged wherein certain types of gait parameters (e.g., spatial vs. temporal vs. spatiotemporal) were differentially associated with certain types of neuropathologies.

\section{Methods}

To identify studies, we utilized the Mayo Clinic Library, and searched the following databases: PubMed, MEDLINE, and Cochrane Libraries from January 21 to April 1, 2016. We searched for studies that examined neuropathology and gait in adult humans using multiple search terms, including "neuropathology," "volumetric decline," "brain atrophy," "brain volume," "cortical thinning," "cortical thickness," "white matter volume," "grey matter volume," "hippocampus volume," "hippocampus atrophy," "FDG PET," "cerebral glucose uptake," "amyloid," “amyloid beta," "PiB-PET," "tau," "gait," and "mobility." We used filters to restrict studies to research conducted in humans and excluding PD patients and falls as an outcome. Searches from PubMed returned 2,016, MEDLINE 974, and Cochrane 13 titles. 
Dementia

Cognitive Disorders
Dement Geriatr Cogn Disord 2017;43:128-143

DOI: 10.1159/000456541

Wennberg et al.: Association between Various Brain Pathologies and Gait Disturbance

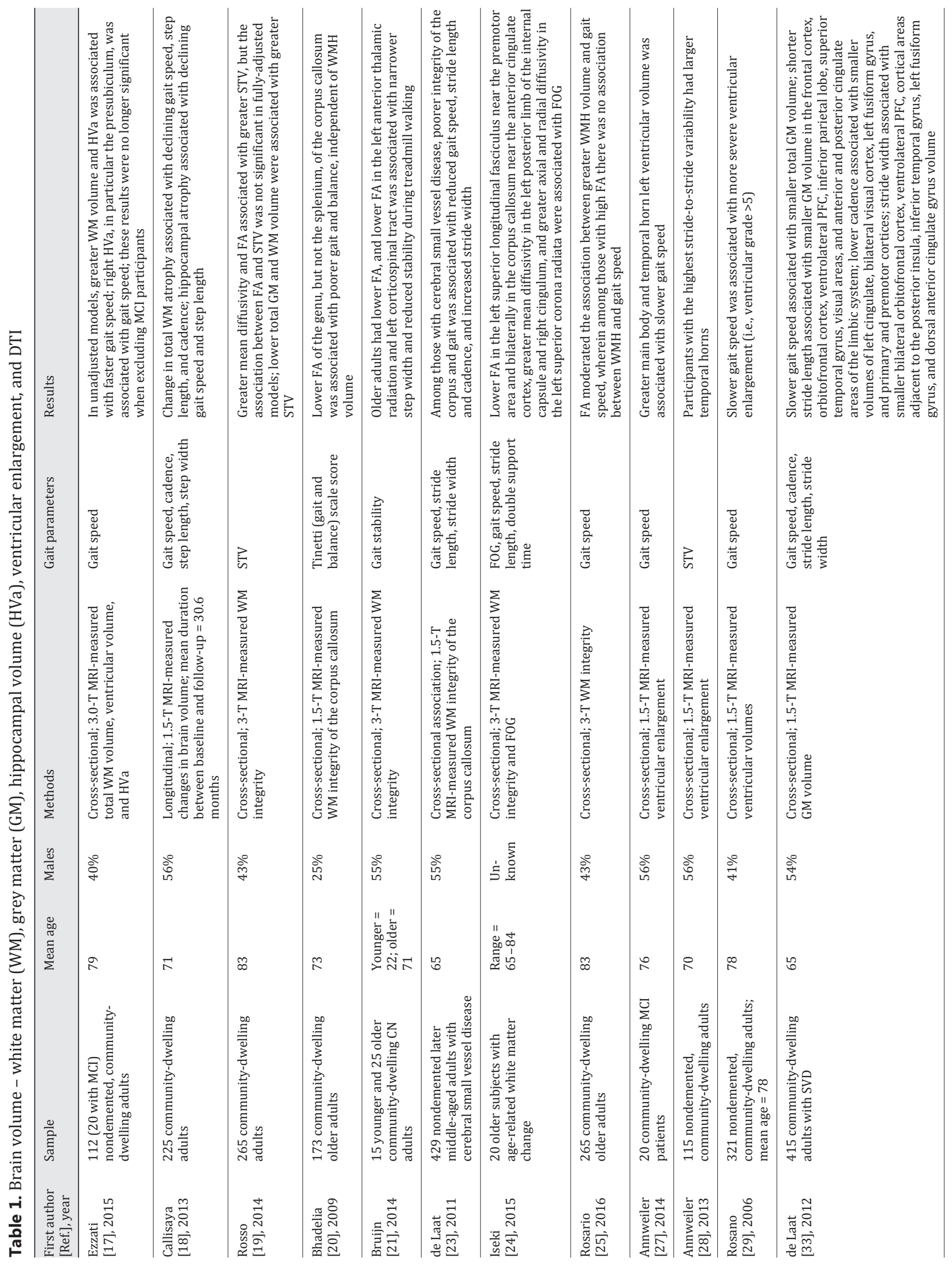


Dementia

Cognitive Disorders

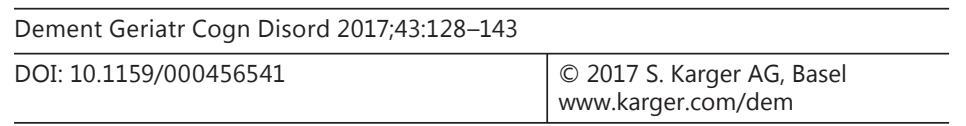

Wennberg et al.: Association between Various Brain Pathologies and Gait Disturbance

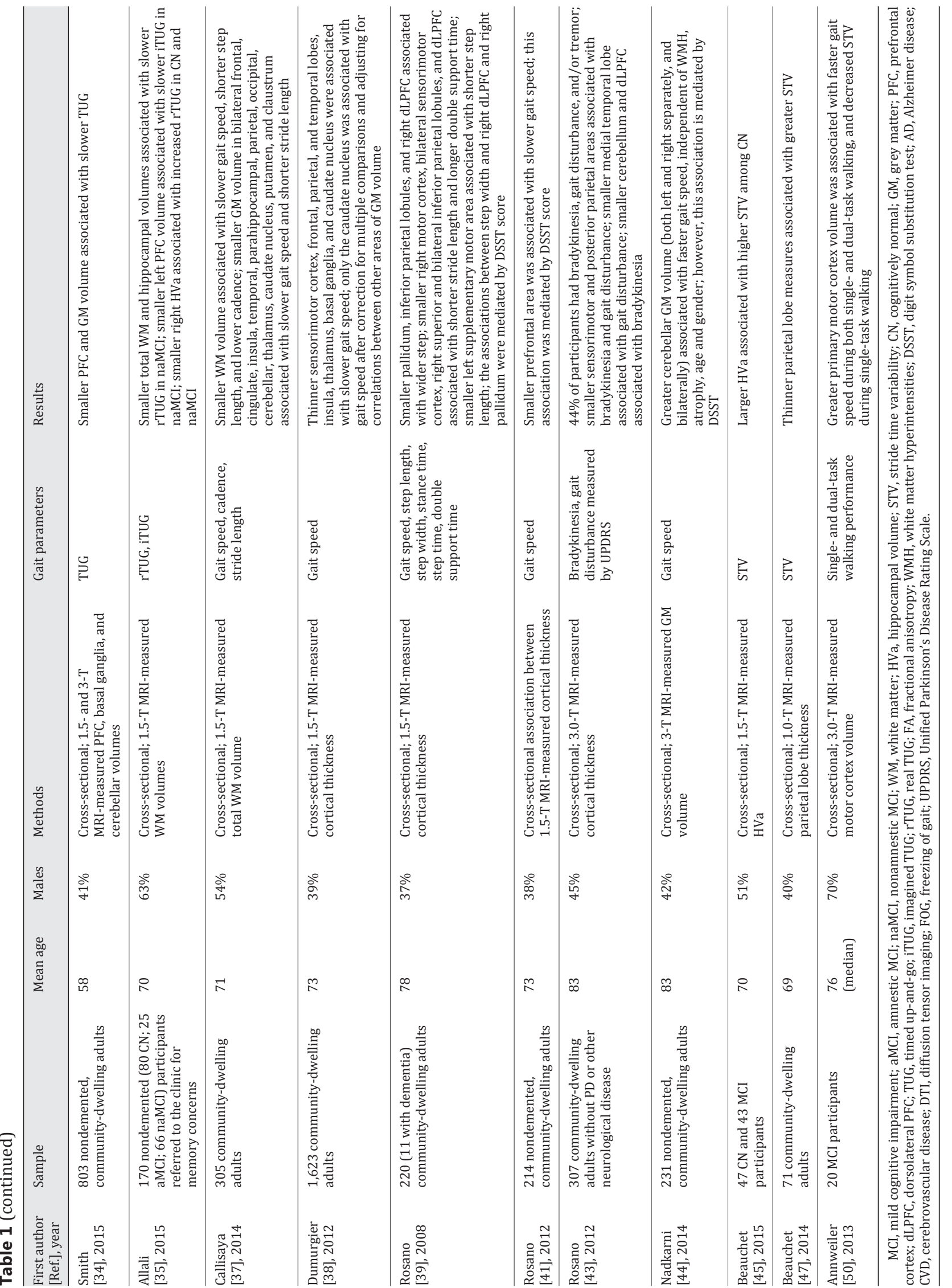


Table 2. Association between glucose uptake and gait

\begin{tabular}{|c|c|c|c|c|c|c|}
\hline $\begin{array}{l}\text { First author } \\
\text { [Ref.], year }\end{array}$ & Sample & $\begin{array}{l}\text { Mean } \\
\text { age }\end{array}$ & Males & Methods & Gait parameters & Results \\
\hline $\begin{array}{l}\text { la Fougere } \\
{[58], 2010}\end{array}$ & 16 healthy adults & 61 & $56 \%$ & $\begin{array}{l}\text { Two time points; } \\
\text { FDG-PET during } \\
\text { locomotion and } 14 \text { days } \\
\text { later at rest }\end{array}$ & $\begin{array}{l}\text { Treadmill walking for } \\
10 \text { min at a constant } \\
\text { rate }\end{array}$ & $\begin{array}{l}\text { Walking associated with increased glucose } \\
\text { uptake in mesial section of the primary cortex, } \\
\text { primary somatosensory cortex, lingual gyrus, } \\
\text { fusiform gyrus, parahippocampal gyrus, } \\
\text { occipital lobe, precuneus, vermal and } \\
\text { paravermal cerebellum, and decreased glucose } \\
\text { uptake in inferior parietal lobe, superior } \\
\text { parietal gyrus, anterior cingulate }\end{array}$ \\
\hline $\begin{array}{l}\text { Shimada } \\
\text { [59], } 2013\end{array}$ & $\begin{array}{l}24 \text { community- } \\
\text { dwelling women, } \\
\text { divided into LSV } \\
\text { and HSV groups }\end{array}$ & 78 & $0 \%$ & $\begin{array}{l}\text { Two time points; } \\
\text { FDG-PET at rest and } \\
\text { during locomotion } 2 \\
\text { days to } 2 \text { weeks apart }\end{array}$ & $\begin{array}{l}\text { Treadmill walking for } \\
25 \text { min at a constant } \\
\text { rate }\end{array}$ & $\begin{array}{l}\text { Sensorimotor areas, occipital lobe, cerebellum } \\
\text { were activated during walking; HSV group had } \\
\text { significant deactivations in the frontal lobe and } \\
\text { the inferior temporal gyrus compared to LSV, } \\
\text { and deactivations of white matter of the middle } \\
\text { and superior temporal gyrus, and hippocampus } \\
\text { during walking compared to at rest; LSV group } \\
\text { had significant activations of the primary } \\
\text { sensorimotor area compared to HSV }\end{array}$ \\
\hline $\begin{array}{l}\text { Sakurai } \\
\text { [61], } 2014\end{array}$ & $\begin{array}{l}182 \text { community- } \\
\text { dwelling women }\end{array}$ & 69 & $0 \%$ & Cross-sectional; FDG-PET & $\begin{array}{l}\text { Gait speed, cadence, } \\
\text { step length at } \\
\text { comfortable and } \\
\text { maximum speed }\end{array}$ & $\begin{array}{l}\text { Slower maximum gait speed and lower cadence } \\
\text { at maximum gait speed was associated with } \\
\text { lower glucose uptake in the PFC, posterior } \\
\text { cingulate, and parietal cortices }\end{array}$ \\
\hline
\end{tabular}

LSV, low step variability; HSV, high step variability; PFC, prefrontal cortex.

Titles were screened for keywords. Abstracts were screened if titles were insufficient. We excluded studies from review if they were conducted in samples of patients with significant medical conditions (e.g., Down syndrome, HD, PD, Creutzfeldt-Jakob), investigated cerebrovascular pathologies, or did not meet our other criteria (i.e., not conducted in humans, only examined falls as an outcome). We included studies for review if they measured both gait and neuropathology either via imaging methods, on autopsy, or in cerebrospinal fluid (CSF) in middle- to older-aged adults. Additional studies were identified from the reference sections of selected papers.

We included 31 studies, 23 of which measured brain volume or tissue integrity and gait, 3 that assessed glucose uptake, 4 that measured $A \beta$, and 1 that assessed tau. These studies are summarized in Tables 1-4. Although the methods of these studies were too heterogeneous to complete a meta-analysis, we did summarize the findings by regions of interest (ROI) (Tables 5 and 6). All studies reviewed met quality guidelines set forth by the National Institutes of Health [16].

\section{White Matter}

Studies that have investigated the association between WM atrophy and gait have focused mostly on total WM, as measured by structural magnetic resonance imaging (MRI). One crosssectional study found, among 112 nondemented community-dwelling adults aged 70 years and older, that greater bilateral total WM was associated with faster gait speed (Table 1). However, this association was not significant after excluding participants with mild cognitive impairment (MCI) [17]. Longitudinally, one study of 225 community-dwelling older adults (mean age $=71$ ) without severe gait impediments or contraindication to MRI reported that change in total WM atrophy was associated with declining gait speed, step length, and cadence over an average of 30 months [18].

Using diffusion tensor imaging techniques, researchers have investigated the association between WM integrity and gait. A study among high-functioning older adults (mean age = 83) found that global greater mean diffusivity (MD) was associated with greater step length variability [19]. Additionally, in 173 community-dwelling older adults (mean age = 73), lower 
Table 3. Association between $A \beta$ and gait

\begin{tabular}{|c|c|c|c|c|c|c|}
\hline $\begin{array}{l}\text { First author } \\
\text { [Ref.], year }\end{array}$ & Sample & Mean age & Males & Methods & Gait parameters & Results \\
\hline $\begin{array}{l}\text { Buchman } \\
{[62], 2008}\end{array}$ & $\begin{array}{l}165 \text { (59 with clinical AD } \\
\text { diagnosis at death) } \\
\text { community-dwelling } \\
\text { adults }\end{array}$ & $\begin{array}{l}85 \text { at } \\
\text { baseline; } 88 \\
\text { at death }\end{array}$ & $44 \%$ & $\begin{array}{l}A D \text { pathology (tau and } \\
A \beta \text { ) at autopsy }\end{array}$ & Gait speed & $\begin{array}{l}\text { AD pathology on autopsy associated } \\
\text { with gait prior to death. }\end{array}$ \\
\hline $\begin{array}{l}\text { Buchman } \\
{[63], 12013}\end{array}$ & $\begin{array}{l}791 \text { community- } \\
\text { dwelling adults }\end{array}$ & $\begin{array}{l}82 \text { at } \\
\text { baseline; } 89 \\
\text { at death }\end{array}$ & $34 \%$ & $\begin{array}{l}A D \text { pathology (tau and } \\
A \beta \text { ) at autopsy }\end{array}$ & Gait speed & $\begin{array}{l}\text { AD pathology on autopsy was } \\
\text { associated with declining gait speed } \\
\text { over an average of } 6.4 \text { years prior to } \\
\text { death }\end{array}$ \\
\hline $\begin{array}{l}\text { del Campo } \\
{[64], 2015}\end{array}$ & $\begin{array}{l}128 \text { non-demented } \\
\text { community-dwelling } \\
\text { adults }\end{array}$ & 76 & $40 \%$ & $\begin{array}{l}\text { Cross-sectional; } \\
{\left[{ }^{18} \mathrm{~F}\right] \text { florbetapir }} \\
\text { PET-measured A } \beta\end{array}$ & Gait speed & $\begin{array}{l}\text { Greater } A \beta \text { deposition in the } \\
\text { posterior and anterior putamen, } \\
\text { caudate, semioval center, precuneus, } \\
\text { anterior and posterior cingulate and } \\
\text { occipital, temporal, and parietal lobes } \\
\text { associated with slower gait speed }\end{array}$ \\
\hline $\begin{array}{l}\text { Wennberg } \\
{[66], 2016}\end{array}$ & $611 \mathrm{CN}$ adults & 63 & $51 \%$ & $\begin{array}{l}\text { Cross-sectional; } \\
\text { PiB-PET SUVR }\end{array}$ & $\begin{array}{l}\text { Gait speed, } \\
\text { cadence, stride } \\
\text { length, double } \\
\text { support time, } \\
\text { stance time } \\
\text { variability }\end{array}$ & $\begin{array}{l}\text { Greater PiB-PET SUVR in prefrontal, } \\
\text { orbitofrontal, parietal, temporal, } \\
\text { anterior cingulate, posterior } \\
\text { cingulate/precuneus, and motor ROIs } \\
\text { was associated with slower gait } \\
\text { speed, lower cadence, longer double } \\
\text { support time, and greater stance time } \\
\text { variability; results were independent } \\
\text { of AD-associated neurodegeneration; } \\
\text { in sex-stratified analyses, results } \\
\text { were significant only among women }\end{array}$ \\
\hline
\end{tabular}

$\mathrm{AD}$, Alzheimer disease; SUVR, standardized uptake value ratio; $\mathrm{CN}$, cognitively normal.

Table 4. Association between tau and gait

\begin{tabular}{|c|c|c|c|c|c|c|}
\hline $\begin{array}{l}\text { First author } \\
\text { [Ref.], year }\end{array}$ & Participants & $\begin{array}{l}\text { Mean } \\
\text { age }\end{array}$ & $\%$ male & Methods & $\begin{array}{l}\text { Gait } \\
\text { parameters }\end{array}$ & Results \\
\hline $\begin{array}{l}\text { Schneider [70], } \\
2006\end{array}$ & $\begin{array}{l}86 \text { Catholic clergy } \\
\text { without PD }\end{array}$ & $\begin{array}{l}85 \text { at } \\
\text { death }\end{array}$ & Not specified & $\begin{array}{l}\text { Neurofibrillary } \\
\text { tangles in the } \\
\text { substantia nigra on } \\
\text { autopsy }\end{array}$ & $\begin{array}{l}\text { Performance on } \\
\text { the UPDRS prior to } \\
\text { death }\end{array}$ & $\begin{array}{l}\text { A greater number of tangles at } \\
\text { death was associated with a } \\
\text { worse score on the UPDRS, with } \\
\text { gait the most strongly affected } \\
\text { domain, independent of } \\
\text { dementia diagnosis }\end{array}$ \\
\hline
\end{tabular}

PD, Parkinson disease; UPDRS, Unified Parkinson's Disease Rating Scale.

fractional anisotropy (FA), indicating less WM microstructural integrity, in the genu, but not the splenium of the corpus callosum, was associated with poorer gait and balance [20]. Importantly, this association was independent of WMH volume. In CN older adults (mean age $=71$ ), lower FA in the left anterior thalamic radiation and left corticospinal tract was associated with reduced step width and greater instability measured during treadmill walking [21]. The corpus callosum is primarily responsible for communication across hemispheres, and the genu primarily connects the left and right prefrontal and anterior frontal cortices [22]. Together, these findings support the idea that integrity of the frontal areas associated with executive function is important for gait and balance, and that gait and balance involve the coordination of multiple areas across hemispheres.

The association between WM integrity within the context of substantial cerebrovascular burden has also been examined. Among 429 nondemented later middle-aged adults (mean 
Table 5. Regions of interest (ROIs) by neuropathology type associated with gait in reviewed papers

\begin{tabular}{|c|c|c|c|c|c|c|}
\hline ROI & WM & GM & $\begin{array}{l}\text { Neuronal } \\
\text { activity }\end{array}$ & $A \beta$ & $\mathrm{Tau}$ & Total \\
\hline Frontal lobe & $x \times x$ & $x \times x \times x \times x$ & $x x$ & & & 12 \\
\hline Parietal lobe & & $x \times x \times x$ & $x x$ & $x$ & & 8 \\
\hline Temporal lobe & $x$ & $x \times x x$ & $x$ & $x$ & & 7 \\
\hline Cerebellum & & $x \times x \times$ & $x x$ & & & 6 \\
\hline Cingulate & & $x x$ & $x x$ & $x$ & & 5 \\
\hline Motor cortex & $x x$ & $x \times x$ & & & & 5 \\
\hline Somatosensory cortex & & $x \times x$ & $x x$ & & & 5 \\
\hline Hippocampus & & $x \times x$ & $x$ & & & 4 \\
\hline Occipital lobe & & $\times$ & $x x$ & $x$ & & 4 \\
\hline Caudate & & $x$ & & $x$ & & 2 \\
\hline Corpus callosum & $x \times x$ & & & & & 3 \\
\hline Insula & & $x \times x$ & & & & 3 \\
\hline Putamen & & $x x$ & & $x$ & & 3 \\
\hline Fusiform gyrus & & $x$ & $x$ & & & 2 \\
\hline Parahippocampal gyrus & & $x$ & $x$ & & & 2 \\
\hline Precuneus & & & $x$ & $x$ & & 2 \\
\hline Thalamus & $x$ & $x$ & & & & 2 \\
\hline Cingulum & $x$ & & & & & 1 \\
\hline Corona radiata & $x$ & & & & & 1 \\
\hline Lingual gyrus & & & $x$ & & & 1 \\
\hline Pallidum & & $x$ & & & & 1 \\
\hline Substantia nigra & & & & & $x$ & 1 \\
\hline Total by pathology type & 12 & 42 & 18 & 7 & 1 & \\
\hline
\end{tabular}

WM, white matter; GM, grey matter; $A \beta$, amyloid beta protein. It should be noted that Buchman et al. [62, 63] investigated the association between $\mathrm{AD}$ pathology (neuritic plaques, diffuse plaques, and neurofibrillary tangles) averaged across midfrontal, superior temporal, inferior parietal, entorhinal, and hippocampal ROIs and gait, so it was not possible to differentiate by ROI or pathology type in these instances.

age $=65$ ) with cerebral small vessel disease, lower FA and higher MD of the corpus callosum was associated with slower gait speed, reduced stride length and cadence, and increased stride width [23]. In a smaller study of 20 older adults (range $=65-84$ ) with significant cerebrovascular pathology, lower FA and higher MD, and axial and radial diffusivity across all WM were associated with freezing of gait [24]. Another study that examined the effect of FA within the context of WMHs found that FA measures throughout WM regions significantly moderated the association between WMH volume and gait speed among 265 community-dwelling older adults (mean age $=83$ ) [25]. Specifically, among those with high FA, there was no association between WMH and gait speed. These results suggest that WMHs alone may not be associated with slower gait and are consistent with the hypothesis that the interaction between multiple pathologies is necessary to substantially affect gait performance [26].

In summary, the evidence presented here suggests that WM atrophy is associated with disrupted gait; however, it is not overwhelmingly compelling, particularly compared to the association between other types of pathology and gait (e.g., GM atrophy), as described below. The few studies investigating the association between gait and WM volume have focused on total volume $[17,18]$. This broad type of investigation may be obscuring regional differences. It may be that more parsed analyses investigating individual regions are needed to detect a stronger association between WM and gait. 
Table 6. Collapsed regions of interest (ROIs) by neuropathology type associated with gait in reviewed papers

\begin{tabular}{|c|c|c|c|c|c|}
\hline ROI & WM & GM & Neuronal activity & $\mathrm{A} \beta$ & Total \\
\hline Frontal lobe & $x \times x$ & $x \times x \times x \times x$ & $x x$ & & 12 \\
\hline Limbic system & $x \times x$ & $x \times x x$ & $x \times x$ & $x$ & 11 \\
\hline Parietal lobe & & $x \times x \times x x x x$ & $x x$ & $x$ & 11 \\
\hline Motor areas & $x \times x$ & $x \times x \times x$ & $x x$ & & 10 \\
\hline Temporal lobe & $x$ & $x \times x x$ & $x$ & $x$ & 7 \\
\hline Cerebellum & & $x \times x x$ & $x x$ & & 6 \\
\hline Basal ganglia & & $x \times x$ & & $x x$ & 5 \\
\hline Occipital lobe & & $x$ & $x x$ & $x$ & 4 \\
\hline Insula & & $x \times x$ & & & 3 \\
\hline Total by pathology type & 10 & 39 & 14 & 6 & \\
\hline
\end{tabular}

WM, white matter; GM, grey matter; $A \beta$, amyloid beta protein. It should be noted that Buchman et al. [62, 63] investigated the association between $\mathrm{AD}$ pathology (neuritic plaques, diffuse plaques, and neurofibrillary tangles) averaged across midfrontal, superior temporal, inferior parietal, entorhinal, and hippocampal ROIs and gait, so it was not possible to differentiate by ROI or pathology type in these instances.

\section{Ventricles}

Ventricular enlargement may be indicative of GM atrophy, declines in CSF reabsorption, and/or total generalized brain atrophy. Among 20 community-dwelling MCI patients (mean age $=76$ ), greater left ventricular volume of both the main bodies and temporal horn was associated with slower gait speed [27] (Table 1). Further, bilateral larger temporal horns were associated with greater stride-to-stride variability among 115 community-dwelling older adults (mean age $=70$ years) [28]. Similarly, among $321 \mathrm{CN}$ and MCI subjects, slower gait speed was associated with severe ventricular enlargement (i.e., ventricular grade $>5$ ) [29]. Ventricular enlargement is a nonspecific measure of cerebral damage, which could explain why the association with gait impairment was only observed with severe ventricular enlargement.

\section{Grey Matter}

GM volume decreases with age, and this decrease is further exacerbated in aging-related diseases such as type 2 diabetes and AD [30-32]. The associations between spatial, temporal, and spatiotemporal gait parameters and reduced cortical thickness have been widespread across cortical regions. Six studies reported that lower total GM volume was associated with poorer performance on multiple gait measures [17, 19, 33-36] (Table 1). Seven studies showed that smaller GM volume in frontal regions was associated with poorer gait [33, 34, 37-41]. Five studies showed a relationship between lower GM volume in the parietal lobe and poorer performance on gait parameters [33, 37-40]. Four studies found that lower GM volume in temporal lobe regions $[37,38,42,43]$, cerebellum $[37,40,43,44]$ and basal ganglia, insula, and limbic systems $[33,37,38,40]$ was associated with disrupted gait. Three studies found that smaller GM volume in motor areas $[33,38,39]$ and the hippocampus were also associated with poorer gait performance $[17,18,45]$.

Across all ROIs reviewed, the association between GM volume in frontal regions and gait was the most commonly reported. This finding supports the hypothesis that gait involves regions important for higher-level cognitive functioning. Indeed, decline in prefrontal ROIs is 
associated with executive dysfunction [46]. The strong relationship reported between the parietal lobe and gait is also not surprising because parietal regions are central to sensory integration, visuospatial function, and managing the relationship between one's self and surroundings [39, 40,47]. Findings that the caudate nucleus is associated with gait are supported from research in PD and HD, which are both characterized by disrupted gait and marked caudate nucleus atrophy [48, 49]. The association between widespread GM atrophy and gait supports the theory that the coordination and interaction of multiple brain regions is necessary for proper gait performance.

The association with GM volume within the context of cerebrovascular pathology has also been examined. De Laat et al. [33] studied the association between cortical thickness and gait within the context of small vessel disease. Among 415 community-dwelling adults (age range 50-85 years) with cerebral small vessel disease, disrupted gait (i.e., slower gait speed, shorter stride length, lower cadence, wider stride width) was associated with lower GM volume across the cortex, including frontal, orbitofrontal, ventrolateral prefrontal, inferior parietal, visual, primary motor and premotor, temporal and left fusiform gyri, visual areas, insula, and cingulate ROIs. Similarly, Smith et al. [34] found that smaller total GM volume, in the context of cerebral small vessel disease, was associated with slower TUG. These findings suggest that even in the context of small vessel disease, widespread GM atrophy in areas associated with cognition and visuospatial processing is associated with disrupted gait.

Additionally, the relationship between GM volume and gait has been explored specifically in MCI. In a smaller study $(n=20)$ of MCI patients, thinner motor cortex measures were associated with slower gait speed in both single and dual task walking, and greater stride time variability during single task walking [50]. Another study examined the association between both GM and WM volumes and mobility in 170 older adults diagnosed as CN, amnestic MCI (aMCI), or nonamnestic MCI (naMCI) [35]. Participants completed both the real TUG (rTUG) and imagined TUG (iTUG). Smaller total GM volume was associated with slower rTUG, and smaller total and left PFC volume was associated with slower iTUG. The strongest association between brain volume and TUG performance was seen in the naMCI group. This may suggest that the pathological changes occurring in naMCI affects motor imagery, and this is independent of the kinesthetic completion of motor tasks (e.g., rTUG).

GM volume has also been associated with more severe measures of motor dysfunction (bradykinesia and gait disturbance), which is prevalent even among older adults without neurological conditions [42, 51, 52]. Among 307 community-dwelling older adults (mean age $=83$ ) without PD, smaller GM sensorimotor cortical and posterior parietal lobe volumes were associated with bradykinesia and gait disturbance. Smaller GM medial temporal lobe volume was associated only with gait disturbance and smaller GM volume in the cerebellum, and dorsolateral prefrontal cortex (dLPFC) was associated only with bradykinesia [43].

Together, the above studies suggest that there is a strong association between GM atrophy and gait. However, there is a paucity of longitudinal evidence, so it is difficult to determine trajectories of atrophy and gait. Indeed, only 1 study [18] examined the association between GM and gait over time. Future studies are also needed to systematically examine specific ROIs and consistently measure multiple gait parameters to elucidate whether GM atrophy in certain ROIs is more or less associated with different gait parameters.

\section{Neuronal Activity}

Glucose uptake is a measure of neuronal activity, and has been shown to decrease in normal aging, with further decline in dementia [53-55]. Greater glucose uptake is indicative of neuronal activation or upregulation, whereas reduced glucose uptake is indicative of deac- 
tivation or downregulation. Based on findings from functional MRI studies, Jahn et al. [56, 57] proposed a supraspinal locomotor network that includes the frontal cortex, basal ganglia, brain stem tegmentum, and cerebellum. This network, which is activated during locomotion across species and can be interrupted by lesions, provides insight into the locomotive process. Their locomotor network hypothesis is supported by findings from a study that examined glucose uptake measured by with fludeoxyglucose $\left({ }^{18} \mathrm{~F}\right.$ ) (FDG)-PET during locomotion in 16 adults aged 51-73 years [58] (Table 2). The greatest uptake was in the bilateral central region, particularly focused in the mesial part of the primary cortex, the primary somatosensory cortex, lingual gyrus, fusiform gyrus, and parahippocampal gyrus during walking. Additionally, the authors observed greater uptake in the occipital lobe and precuneus. The first group of brain areas is associated with visually guided navigation, while the latter areas are associated with visual-motor coordination.

A study that measured glucose uptake in 24 community-dwelling women aged 75-82 years similarly found greater glucose uptake in the occipital lobe, as well as the sensorimotor area and cerebellum during treadmill walking [59]. Their results showed reduced uptake in the orbitofrontal and superior frontal gyrus, dLPFC, supplementary motor area, middle and superior temporal gyrus, posterior cingulate cortex, pons, and hippocampus. Another study separated participants into low step variability (LSV) and high step variability (HSV) groups, because, as aforementioned, greater step variability is associated with increased risk of negative clinical outcomes [4,5]. The LSV group showed greater sensorimotor activation than the HSV group. Additionally, the HSV group had relative deactivation of the supplementary motor area, dLPFC, and hippocampus during treadmill walking. The authors hypothesized that deactivation, as assessed by lower glucose uptake, of the supplementary motor area and dLPFC in the HSV group indicate that these participants found it more difficult to adapt to the novel walking environment (i.e., the treadmill). The observed greater activation of the hippocampus is in line with earlier findings [60], indicating that hippocampal metabolism and atrophy are associated with greater step length variability. In contrast, lower glucose uptake in the prefrontal, posterior cingulate, and parietal cortices was associated with slower maximum walking speed and lower cadence at maximum walking speed among $182 \mathrm{com}$ munity-dwelling women aged 55-89 years [61]. This finding indicates that lower neural activation, as opposed to increased neural activation, is associated with poorer gait.

Associations between gait and cerebral glucose uptake are diffuse across brain regions, including frontal, temporal, parietal, and occipital lobes, and the cerebellum and limbic areas. This is consistent with the hypothesis put forth by Jahn et al. [56, 57], indicating that locomotion requires coordination of multiple brain regions, including those involved in higher-level cognition. It is unclear, however, whether higher glucose uptake (which suggests upregulation and recruitment of brain regions) is needed to execute gait, or lower glucose uptake (which suggests cerebral dysfunction) is associated with gait. For example, the study from Shimada et al. [59] found HSV participants had lower glucose uptake in sensorimotor areas, but higher glucose uptake in the hippocampus. It may be that different brain regions respond contrarily to the demands of gait functioning, and therefore have varying glucose uptake patterns. Longitudinal studies will be critical for understanding these associations to determine whether decreased and/or increased glucose uptake, perhaps dependent on the ROI, predicts gait decline.

\section{Amyloid Beta}

Over $30 \%$ of adults over the age of 70 have substantial cerebral $A \beta$ deposition [13]. However, few studies have investigated the association between $A \beta$ and gait. Two autopsy studies reported that greater AD pathology (neuritic plaques, diffuse plaques, and neurofi- 
brillary tangles) deposition in the midfrontal, superior temporal, inferior parietal, entorhinal cortices, and hippocampus was associated with reduced gait speed prior to death and declining gait speed up to 6 years prior to death [62, 63] (Table 3). A study in 128 nondemented older adults (aged 70 years or older) found that greater $A \beta$ deposition in the putamen, caudate, precuneus, and occipital, temporal, and parietal lobes was associated with slower gait speed [64]. The association was strongest for $A \beta$ deposition in the posterior putamen. Given its proximity to the motor corticostriatal circuits, this finding suggests that $A \beta$ deposition contributes to gait dysfunction.

Expanding on this study, we investigated the association between $\mathrm{C}^{11}$ Pittsburgh Compound B (PiB) [65] PET standardized uptake volume ration (SUVR) and gait parameters in CN adults aged 50-69 [66]. Greater PiB-PET SUVR across ROIs (prefrontal, orbitofrontal, temporal, parietal, anterior and posterior cingulate, and motor) was associated with slower gait speed, lower cadence, longer double support time, and greater stance time variability, independent of neurodegeneration, as measured by FDG-PET and MRI, in AD-signature regions. In sex-stratified analyses, these associations were only significant among women. In conclusion, despite the relatively few studies that have investigated the association between $A \beta$ and gait, it appears that greater $A \beta$ burden is associated with disrupted gait. Longitudinal studies are needed to determine the trajectories between amyloidosis and gait.

\section{Tau}

Aggregates of tau protein are part of the pathological process of a number of diseases, including $\mathrm{AD}$ and frontotemporal dementia. The majority of research examining the association between gait and tau has been conducted in $\mathrm{AD}$ and normal pressure hydrocephalus (NPH) patients [67-69]. However, one study among 86 participants without PD (or AD or $\mathrm{NPH}$ ) reported that the number of neurofibrillary tangles in the substantia nigra was significantly associated with declining gait in annual exams prior to death [70]. This evidence suggests that gait and mobility are impacted by tau aggregation both in diagnosed and prodromal disease. With the new availability of tau-PET ligands, imaging will provide information on whether regional deposition of cerebral tau affects gait in vivo, which cannot currently be ascertained by measuring tau in the CSF.

\section{Summary of the Reported Brain Regions Associated with Gait}

Pathologies in 3 regions were most often found to be associated with disrupted gait: the frontal regions were associated with gait in 12 studies, and the limbic system and parietal regions, were each associated with gait in 11 studies (Tables 5 and 6). Although there was not strong evidence for the association between the motor cortices and gait, the motor cortex and somatosensory motor cortex are located in the frontal and parietal lobes, respectively, and are a juncture of the inputs from multiple converging cortical and subcortical regions, such as the frontal lobe and thalamus. Further, the motor areas provide input to the descending corticospinal tract $[50,71]$. The observed association of the limbic system with gait further suggests that cognition, especially memory, is important for gait. Indeed, past studies have suggested that gait requires memory, particularly in novel situations $[35,45,59,60]$. Thus, other regions associated with gait and cognitive functioning (e.g., frontal and parietal regions) may impact gait partially through cognitive dysfunction. For additional information, the association between cognition and gait has been reviewed elsewhere [72]. 


\section{Gaps in the Literature and Future Directions}

Future studies should consider potential sex differences in the association between neuropathologies and gait. Past studies have shown that this relationship can differ between men and women [66]. This is unsurprising given the increased recognition of sex differences in aging $[73,74]$, gait changes $[73,75-78]$, and brain and neuropathological development [50, 79-85]. An empirical understanding of sexual dimorphism across pathologies is important. Reasonably, these differences in pathology would translate to differing patterns of gait dysfunction. Thus, future research should attempt to delineate how different pathologies affect different gait parameters by sex. This may translate into sex-specific clinical guidelines for gait impairment associated with brain pathology. Moreover, most studies in this review investigated the association between a particular pathology and gait speed. However, it is important to examine other gait parameters to determine whether they are differentially affected by specific pathologies, show different trajectories of decline, or have sex-specific differences.

Perhaps the most glaring gap in the literature is the lack of longitudinal studies. Of the research we reviewed, only 2 studies $[18,63]$ had a longitudinal design. Longitudinal studies are needed to determine how gait trajectories are affected by changes in neuropathology over time. Quantifying trajectories of pathology, based on both type and location, with gait decline will allow for a more precise approach to utilizing gait as a measure in clinic and for therapeutic and intervention trials.

\section{Conclusion}

The goal of this review was to summarize research examining the associations between neuropathologies and gait. We found that all pathologies reviewed (i.e., WM, GM, and HVa decline, ventricular enlargement, and amyloid and tau aggregation) were associated with poorer gait performance. The strongest associations were between GM and gait. Regardless, this review further suggests a link between neurodegenerative biomarkers and gait performance.

This review has limitations that should be considered. First, relatively little research has been conducted investigating the association between protein aggregation (i.e., $\mathrm{A} \beta$ and tau) and gait, in part because PET ligands have only recently been developed, so it is difficult to draw robust conclusions. However, past reviews have not included these studies, and we hope more research will be conducted investigating the association between protein aggregation and gait. Additionally, we were unable to conduct a meta-analysis due to the heterogeneity of the methods for measuring both neuropathology and gait. For example, some studies used voxel count methods to determine volume while others used ROI methods. These methods produce comparable, but heterogeneous results [86], and more research is needed to make direct comparisons between these methods [87]. Without a meta-analysis, it is difficult to come to quantitative conclusions about findings in the literature, including determining whether gait parameters were differentially associated with different neuropathologies. Still, we hope this review sheds light on the emerging field of research investigating the link between neuropathologies and gait.

Multiple studies have been published since Rosso et al. [7] put out the call to better understand the connection between the CNS and gait. However, more research is needed to develop a deeper understanding of the link between neurological mechanisms and different facets of gait and mobility [88]. An empirical quantification of the association between neuropathology and gait parameters will contribute to the increased use of gait measures in the clinic and for 
clinical trials. Gait has been identified as a potentially useful clinical tool [89]. This is largely because it is easy to measure and it is associated with several poor clinical outcomes. Understanding and interpreting specific declines in gait parameters throughout the aging process, beginning as early as middle age, could be important to prevent future poor clinical outcomes [8].

\section{Acknowledgment}

This work was supported by NIH grant R01 AG049704.

\section{Disclosure Statement}

Drs. Wennberg and Savica report no disclosures. Dr. Mielke served as a consultant to Lysosomal Therapeutics Inc. and receives research support from the National Institute on Aging, National Institutes of Health, and the Michael J. Fox Foundation.

\section{Author Contributions}

All authors contributed to the drafting and critical revision of the manuscript.

\section{References}

1 Verghese J, LeValley A, Hall CB, Katz MJ, Ambrose AF, Lipton RB: Epidemiology of gait disorders in communityresiding older adults. J Am Geriatr Soc 2006;54:255-261.

2 Abellan van Kan G, Rolland Y, Andrieu S, Bauer J, Beauchet O, Bonnefoy M, Cesari M, Donini LM, Gillette Guyonnet S, Inzitari M, Nourhashemi F, Onder G, Ritz P, Salva A, Visser M, Vellas B: Gait speed at usual pace as a predictor of adverse outcomes in community-dwelling older people an International Academy on Nutrition and Aging (IANA) Task Force. J Nutr Health Aging 2009;13:881-889.

3 Mielke MM, Roberts RO, Savica R, Cha R, Drubach DI, Christianson T, Pankratz VS, Geda YE, Machulda MM, Ivnik RJ, Knopman DS, Boeve BF, Rocca WA, Petersen RC: Assessing the temporal relationship between cognition and gait: slow gait predicts cognitive decline in the Mayo Clinic Study of Aging. J Gerontol A Biol Sci Med Sci 2013;68:929-937.

4 Brach JS, Wert D, VanSwearingen JM, Newman AB, Studenski SA: Use of stance time variability for predicting mobility disability in community-dwelling older persons: a prospective study. J Geriatr Phys Ther 2012;35: 112-117.

5 Verghese J, Wang C, Lipton RB, Holtzer R, Xue X: Quantitative gait dysfunction and risk of cognitive decline and dementia. J Neurol Neurosurg Psychiatry 2007;78:929-935.

6 Podsiadlo D, Richardson S: The timed "Up \& Go": a test of basic functional mobility for frail elderly persons. J Am Geriatr Soc 1991;39:142-148.

7 Rosso AL, Studenski SA, Chen WG, Aizenstein HJ, Alexander NB, Bennett DA, Black SE, Camicioli R, Carlson MC, Ferrucci L, Guralnik JM, Hausdorff JM, Kaye J, Launer LJ, Lipsitz LA, Verghese J, Rosano C: Aging, the central nervous system, and mobility. J Gerontol A Biol Sci Med Sci 2013;68:1379-1386.

8 Ferrucci L, Cooper R, Shardell M, Simonsick EM, Schrack JA, Kuh D: Age-related change in mobility: perspectives from life course epidemiology and geroscience. J Gerontol A Biol Sci Med Sci 2016

9 Markesbery WR, Schmitt FA, Kryscio RJ, Davis DG, Smith CD, Wekstein DR: Neuropathologic substrate of mild cognitive impairment. Arch Neurol 2006;63:38-46.

10 Schneider JA, Arvanitakis Z, Leurgans SE, Bennett DA: The neuropathology of probable Alzheimer disease and mild cognitive impairment. Ann Neurol 2009;66:200-208.

11 Sonnen JA, Santa Cruz K, Hemmy LS, Woltjer R, Leverenz JB, Montine KS, Jack CR, Kaye J, Lim K, Larson EB, White L, Montine TJ: Ecology of the aging human brain. Arch Neurol 2011;68:1049-1056.

12 White L: Brain lesions at autopsy in older Japanese-American men as related to cognitive impairment and dementia in the final years of life: a summary report from the Honolulu-Asia aging study. J Alzheimers Dis 2009;18:713-725.

13 Mielke MM, Wiste HJ, Weigand SD, Knopman DS, Lowe VJ, Roberts RO, Geda YE, Swenson-Dravis DM, Boeve BF, Senjem ML, Vemuri P, Petersen RC, Jack CR Jr: Indicators of amyloid burden in a population-based study of cognitively normal elderly. Neurology 2012;79:1570-1577. 
14 Annweiler C, Montero-Odasso M: Vascular burden as a substrate for higher-level gait disorders in older adults. A review of brain mapping literature. Panminerva Med 2012;54:189-204.

15 Zheng JJ, Delbaere K, Close JC, Sachdev PS, Lord SR: Impact of white matter lesions on physical functioning and fall risk in older people: a systematic review. Stroke 2011;42:2086-2090.

16 National Institutes of Health: Quality Assessment Tool for Observational Cohort and Cross-Sectional Studies, Bethesda, National Institutes of Health, 2014.

17 Ezzati A, Katz MJ, Lipton ML, Lipton RB, Verghese J: The association of brain structure with gait velocity in older adults: a quantitative volumetric analysis of brain MRI. Neuroradiology 2015;57:851-861.

18 Callisaya ML, Beare R, Phan TG, Blizzard L, Thrift AG, Chen J, Srikanth VK: Brain structural change and gait decline: a longitudinal population-based study. J Am Geriatr Soc 2013;61:1074-1079.

19 Rosso AL, Olson Hunt MJ, Yang M, Brach JS, Harris TB, Newman AB, Satterfield S, Studenski SA, Yaffe K, Aizenstein HJ, Rosano C: Higher step length variability indicates lower gray matter integrity of selected regions in older adults. Gait Posture 2014;40:225-230.

20 Bhadelia RA, Price LL, Tedesco KL, Scott T, Qiu WQ, Patz S, Folstein M, Rosenberg I, Caplan LR, Bergethon P: Diffusion tensor imaging, white matter lesions, the corpus callosum, and gait in the elderly. Stroke 2009;40: 3816-3820.

21 Bruijn SM, Van Impe A, Duysens J, Swinnen SP: White matter microstructural organization and gait stability in older adults. Front Aging Neurosci 2014;6:104.

22 Schmahmann PD, Pandya DN: Fiber Pathways of the Brain. New York, Oxford Univeristy Press, 2006.

23 de Laat KF, Tuladhar AM, van Norden AG, Norris DG, Zwiers MP, de Leeuw FE: Loss of white matter integrity is associated with gait disorders in cerebral small vessel disease. Brain 2011;134:73-83.

24 Iseki K, Fukuyama H, Oishi N, Tomimoto H, Otsuka Y, Nankaku M, Benninger D, Hallett M, Hanakawa T: Freezing of gait and white matter changes: a tract-based spatial statistics study. J Clin Mov Disord 2015;2:1.

25 Rosario BL, Rosso AL, Aizenstein HJ, Harris T, Newman AB, Satterfield S, Studenski SA, Yaffe K, Rosano C: Cerebral white matter and slow gait: contribution of hyperintensities and normal-appearing parenchyma. J Gerontol A Biol Sci Med Sci 2016;71:968-973.

26 Choi P, Ren M, Phan TG, Callisaya M, Ly JV, Beare R, Chong W, Srikanth V: Silent infarcts and cerebral microbleeds modify the associations of white matter lesions with gait and postural stability: population-based study. Stroke 2012;43:1505-1510.

27 Annweiler C, Beauchet 0, Bartha R, Montero-Odasso M: Slow gait in MCI is associated with ventricular enlargement: results from the Gait and Brain Study. J Neural Transm (Vienna) 2013;120:1083-1092.

28 Annweiler C, Montero-Odasso M, Bartha R, Drozd J, Hachinski V, Beauchet O: Association between gait variability and brain ventricle attributes: a brain mapping study. Exp Gerontol 2014;57:256-263.

29 Rosano C, Brach J, Longstreth Jr WT, Newman AB: Quantitative measures of gait characteristics indicate prevalence of underlying subclinical structural brain abnormalities in high-functioning older adults. Neuroepidemiology 2006;26:52-60.

30 Dickerson BC, Bakkour A, Salat DH, Feczko E, Pacheco J, Greve DN, Grodstein F, Wright CI, Blacker D, Rosas HD, Sperling RA, Atri A, Growdon JH, Hyman BT, Morris JC, Fischl B, Buckner RL: The cortical signature of Alzheimer's disease: regionally specific cortical thinning relates to symptom severity in very mild to mild AD dementia and is detectable in asymptomatic amyloid-positive individuals. Cereb Cortex 2009;19:497-510.

31 Moran C, Phan TG, Chen J, Blizzard L, Beare R, Venn A, Munch G, Wood AG, Forbes J, Greenaway TM, Pearson $\mathrm{S}$, Srikanth V: Brain atrophy in type 2 diabetes: regional distribution and influence on cognition. Diabetes Care 2013;36:4036-4042.

32 Thambisetty M, Wan J, Carass A, An Y, Prince JL, Resnick SM: Longitudinal changes in cortical thickness associated with normal aging. Neuroimage 2010;52:1215-1223.

33 de Laat KF, Reid AT, Grim DC, Evans AC, Kotter R, van Norden AG, de Leeuw FE: Cortical thickness is associated with gait disturbances in cerebral small vessel disease. Neuroimage 2012;59:1478-1484.

34 Smith EE, O’Donnell M, Dagenais G, Lear SA, Wielgosz A, Sharma M, Poirier P, Stotts G, Black SE, Strother S, Noseworthy MD, Benavente O, Modi J, Goyal M, Batool S, Sanchez K, Hill V, McCreary CR, Frayne R, Islam S, DeJesus J, Rangarajan S, Teo K, Yusuf S: Early cerebral small vessel disease and brain volume, cognition, and gait. Ann Neurol 2015;77:251-261.

35 Allali G, Annweiler C, Predovan D, Bherer L, Beauchet O: Brain volume changes in gait control in patients with mild cognitive impairment compared to cognitively healthy individuals; GAIT study results. Exp Gerontol 2016;76:72-79.

36 Doi T, Shimada H, Makizako H, Tsutsumimoto K, Hotta R, Nakakubo S, Suzuki T: Effects of white matter lesions on trunk stability during dual-task walking among older adults with mild cognitive impairment. Age (Dordrecht) 2015;37:120.

37 Callisaya ML, Beare R, Phan TG, Chen J, Srikanth VK: Global and regional associations of smaller cerebral gray and white matter volumes with gait in older people. PLoS One 2014;9:e84909.

38 Dumurgier J, Crivello F, Mazoyer B, Ahmed I, Tavernier B, Grabli D, Francois C, Tzourio-Mazoyer N, Tzourio C, Elbaz A: MRI atrophy of the caudate nucleus and slower walking speed in the elderly. Neuroimage 2012;60: 871-878.

39 Rosano C, Aizenstein H, Brach J, Longenberger A, Studenski S, Newman AB: Special article: gait measures indicate underlying focal gray matter atrophy in the brain of older adults. J Gerontol A Biol Sci Med Sci 2008; 63:1380-1388. 
40 Rosano C, Aizenstein HJ, Studenski S, Newman AB: A regions-of-interest volumetric analysis of mobility limitations in community-dwelling older adults. J Gerontol A Biol Sci Med Sci 2007;62:1048-1055.

41 Rosano C, Studenski SA, Aizenstein HJ, Boudreau RM, Longstreth WT Jr, Newman AB: Slower gait, slower information processing and smaller prefrontal area in older adults. Age Ageing 2012;41:58-64.

42 de Laat KF, van Norden AG, van Oudheusden LJ, van Uden IW, Norris DG, Zwiers MP, de Leeuw FE: Diffusion tensor imaging and mild parkinsonian signs in cerebral small vessel disease. Neurobiol Aging 2012;33:21062112.

43 Rosano C, Bennett DA, Newman AB, Venkatraman V, Yaffe K, Harris T, Kritchevsky S, Aizenstein HJ: Patterns of focal gray matter atrophy are associated with bradykinesia and gait disturbances in older adults. J Gerontol A Biol Sci Med Sci 2012;67:957-962.

44 Nadkarni NK, Nunley KA, Aizenstein H, Harris TB, Yaffe K, Satterfield S, Newman AB, Rosano C: Association between cerebellar gray matter volumes, gait speed, and information-processing ability in older adults enrolled in the Health ABC study. J Gerontol A Biol Sci Med Sci 2014;69:996-1003.

45 Beauchet $\mathrm{O}$, Launay CP, Annweiler C, Allali G: Hippocampal volume, early cognitive decline and gait variability: which association? Exp Gerontol 2015;61:98-104.

46 Yogev-Seligmann G, Hausdorff JM, Giladi N: The role of executive function and attention in gait. Mov Disord 2008;23:329-342; quiz 472.

47 Beauchet O, Annweiler C, Celle S, Bartha R, Barthelemy JC, Roche F: Higher gait variability is associated with decreased parietal gray matter volume among healthy older adults. Brain Topogr 2014;27:293-295.

48 Finelli PF, Gupta F, Zeevi N: Neuroimaging of bilateral caudate infarction manifesting as Parkinsonian gait disorder. Conn Med 2007;71:149-150.

49 Rao AK, Muratori L, Louis ED, Moskowitz CB, Marder KS: Spectrum of gait impairments in presymptomatic and symptomatic Huntington's disease. Mov Disord 2008;23:1100-1107.

50 Annweiler C, Beauchet O, Bartha R, Wells JL, Borrie MJ, Hachinski V, Montero-Odasso M: Motor cortex and gait in mild cognitive impairment: a magnetic resonance spectroscopy and volumetric imaging study. Brain 2013; 136:859-871.

51 Bennett DA, Beckett LA, Murray AM, Shannon KM, Goetz CG, Pilgrim DM, Evans DA: Prevalence of parkinsonian signs and associated mortality in a community population of older people. N Engl J Med 1996;334:71-76.

52 Racette BA, Good LM, Kissel AM, Criswell SR, Perlmutter JS: A population-based study of parkinsonism in an Amish community. Neuroepidemiology 2009;33:225-230.

53 Chen Z, Zhong C: Decoding Alzheimer's disease from perturbed cerebral glucose metabolism: implications for diagnostic and therapeutic strategies. Prog Neurobiol 2013;108:21-43.

54 Petit-Taboue MC, Landeau B, Desson JF, Desgranges B, Baron JC: Effects of healthy aging on the regional cerebral metabolic rate of glucose assessed with statistical parametric mapping. Neuroimage 1998;7:176-184.

55 Shen X, Liu H, Hu Z, Hu H, Shi P: The relationship between cerebral glucose metabolism and age: report of a large brain PET data set. PLoS One 2012;7:e51517.

56 Jahn K, Deutschlander A, Stephan T, Kalla R, Hufner K, Wagner J, Strupp M, Brandt T: Supraspinal locomotor control in quadrupeds and humans. Prog Brain Res 2008;171:353-362.

57 Jahn K, Deutschlander A, Stephan T, Kalla R, Wiesmann M, Strupp M, Brandt T: Imaging human supraspinal locomotor centers in brainstem and cerebellum. Neuroimage 2008;39:786-792.

58 la Fougere C, Zwergal A, Rominger A, Forster S, Fesl G, Dieterich M, Brandt T, Strupp M, Bartenstein P, Jahn K: Real versus imagined locomotion: a [18F]-FDG PET-fMRI comparison. Neuroimage 2010;50:1589-1598.

59 Shimada H, Ishii K, Ishiwata K, Oda K, Suzukawa M, Makizako H, Doi T, Suzuki T: Gait adaptability and brain activity during unaccustomed treadmill walking in healthy elderly females. Gait Posture 2013;38:203-208.

60 Zimmerman ME, Lipton RB, Pan JW, Hetherington HP, Verghese J: MRI- and MRS-derived hippocampal correlates of quantitative locomotor function in older adults. Brain Res 2009;1291:73-81.

61 Sakurai R, Fujiwara Y, Yasunaga M, Takeuchi R, Murayama Y, Ohba H, Sakuma N, Suzuki H, Oda K, Sakata M, Toyohara J, Ishiwata K, Shinkai S, Ishii K: Regional cerebral glucose metabolism and gait speed in healthy community-dwelling older women. J Gerontol A Biol Sci Med Sci 2014;69:1519-1527.

62 Buchman AS, Schneider JA, Leurgans S, Bennett DA: Physical frailty in older persons is associated with Alzheimer disease pathology. Neurology 2008;71:499-504.

63 Buchman AS, Yu L, Wilson RS, Schneider JA, Bennett DA: Association of brain pathology with the progression of frailty in older adults. Neurology 2013;80:2055-2061.

64 del Campo N, Payoux P, Djilali A, Delrieu J, Hoogendijk EO, Rolland Y, Cesari M, Weiner MW, Andrieu S, Vellas B: Relationship of regional brain beta-amyloid to gait speed. Neurology 2016;86:36-43.

65 Klunk WE, Engler H, Nordberg A, Wang Y, Blomqvist G, Holt DP, Bergstrom M, Savitcheva I, Huang GF, Estrada S, Ausen B, Debnath ML, Barletta J, Price JC, Sandell J, Lopresti BJ, Wall A, Koivisto P, Antoni G, Mathis CA, Langstrom B: Imaging brain amyloid in Alzheimer's disease with Pittsburgh Compound-B. Ann Neurol 2004;55: 306-319.

66 Wennberg AM, Savica R, Hagen CE, Roberts RO, Knopman DS, Hollman JH, Vemuri P, Jack CR Jr, Petersen RC, Mielke MM: Cerebral amyloid deposition is associated with gait parameters in the Mayo Clinic Study of Aging. J Am Geriatr Soc, Epub ahead of print.

67 Kubo Y, Kazui H, Yoshida T, Kito Y, Kimura N, Tokunaga H, Ogino A, Miyake H, Ishikawa M, Takeda M: Validation of grading scale for evaluating symptoms of idiopathic normal-pressure hydrocephalus. Dement Geriatr Cogn Disord 2008;25:37-45. 
68 Kang K, Ko PW, Jin M, Suk K, Lee HW: Idiopathic normal-pressure hydrocephalus, cerebrospinal fluid biomarkers, and the cerebrospinal fluid tap test. J Clin Neurosci 2014;21:1398-1403.

69 Attems J, Quass M, Jellinger KA: Tau and alpha-synuclein brainstem pathology in Alzheimer disease: relation with extrapyramidal signs. Acta Neuropathol 2007;113:53-62.

70 Schneider JA, Li JL, Li Y, Wilson RS, Kordower JH, Bennett DA: Substantia nigra tangles are related to gait impairment in older persons. Ann Neurol 2006;59:166-173.

71 Graziano MS, Taylor CS, Moore T, Cooke DF: The cortical control of movement revisited. Neuron 2002;36: 349-362.

72 Kearney FC, Harwood RH, Gladman JR, Lincoln N, Masud T: The relationship between executive function and falls and gait abnormalities in older adults: a systematic review. Dement Geriatr Cogn Disord 2013;36:20-35.

73 Frimenko R, Goodyear C, Bruening D: Interactions of sex and aging on spatiotemporal metrics in non-pathological gait: a descriptive meta-analysis. Physiotherapy 2015;101:266-272.

74 Li R, Singh M: Sex differences in cognitive impairment and Alzheimer's disease. Front Neuroendocrinol 2014; 35:385-403.

75 Auvinet B, Berrut G, Touzard C, Moutel L, Collet N, Chaleil D, Barrey E: Reference data for normal subjects obtained with an accelerometric device. Gait Posture 2002;16:124-134.

76 Callisaya ML, Blizzard L, Schmidt MD, McGinley JL, Srikanth VK: Sex modifies the relationship between age and gait: a population-based study of older adults. J Gerontol A Biol Sci Med Sci 2008;63:165-170.

77 Doyo W, Kozakai R, Kim HY, Ando F, Shimokata H: Spatiotemporal components of the 3-D gait analysis of community-dwelling middle-aged and elderly Japanese: age- and sex-related differences. Geriatr Gerontol Int 2011;11:39-49.

78 Oberg T, Karsznia A, Oberg K: Basic gait parameters: reference data for normal subjects, 10-79 years of age. J Rehabil Res Dev 1993;30:210-223.

79 Goldstein JM, Seidman LJ, Horton NJ, Makris N, Kennedy DN, Caviness VS Jr, Faraone SV, Tsuang MT: Normal sexual dimorphism of the adult human brain assessed by in vivo magnetic resonance imaging. Cereb Cortex 2001;11:490-497.

80 Chen X, Sachdev PS, Wen W, Anstey KJ: Sex differences in regional gray matter in healthy individuals aged 44-48 years: a voxel-based morphometric study. Neuroimage 2007;36:691-699.

81 Hu Y, Xu Q, Li K, Zhu H, Qi R, Zhang Z, Lu G: Gender differences of brain glucose metabolic networks revealed by FDG-PET: evidence from a large cohort of 400 young adults. PLoS One 2013;8:e83821.

82 Jack CR Jr, Wiste HJ, Weigand SD, Knopman DS, Vemuri P, Mielke MM, Lowe V, Senjem ML, Gunter JL, Machulda MM, Gregg BE, Pankratz VS, Rocca WA, Petersen RC: Age, sex, and APOE epsilon4 effects on memory, brain structure, and beta-amyloid across the adult life span. JAMA Neurol 2015;72:511-519.

83 Kruggel F: MRI-based volumetry of head compartments: normative values of healthy adults. Neuroimage 2006;30:1-11.

84 Oliveira-Pinto AV, Andrade-Moraes CH, Oliveira LM, Parente-Bruno DR, Santos RM, Coutinho RA, Alho AT, Leite RE, Suemoto CK, Grinberg LT, Pasqualucci CA, Jacob-Filho W, Lent R: Do age and sex impact on the absolute cell numbers of human brain regions? Brain Struct Funct 2016;221:3547-3559.

85 Steffen TM, Hacker TA, Mollinger L: Age- and gender-related test performance in community-dwelling elderly people: Six-Minute Walk Test, Berg Balance Scale, Timed Up \& Go Test, and gait speeds. Phys Ther 2002;82: 128-137.

86 Grimm O, Pohlack S, Cacciaglia R, Winkelmann T, Plichta MM, Demirakca T, Flor H: Amygdalar and hippocampal volume: a comparison between manual segmentation, Freesurfer and VBM. J Neurosci Methods 2015; 253:254-261.

87 Stein JL, Medland SE, Vasquez AA, Hibar DP, Senstad RE, Winkler AM, Toro R, et al: Identification of common variants associated with human hippocampal and intracranial volumes. Nat Genet 2012;44:552-561.

88 Sorond FA, Cruz-Almeida Y, Clark DJ, Viswanathan A, Scherzer CR, De Jager P, Csiszar A, Laurienti PJ, Hausdorff JM, Chen WG, Ferrucci L, Rosano C, Studenski SA, Black SE, Lipsitz LA: Aging, the central nervous system, and mobility in older adults: neural mechanisms of mobility impairment. J Gerontol A Biol Sci Med Sci 2015;70: 1526-1532.

89 Fritz S, Lusardi M: White paper: “walking speed: the sixth vital sign.” J Geriatr Phys Ther 2009;32:46-49. 